\title{
Homo sapiens schafft sich ab
}

\section{Erhard Taverna}

\author{
Zur Zeit Mary Shelleys war Elektrizität alles. Es war möglich, aus Leichenteilen einen Frankenstein \\ zu erfinden. Noch Lenin definierte seinen Kommunismus als Sowjetmacht plus Elektrifizierung.
}

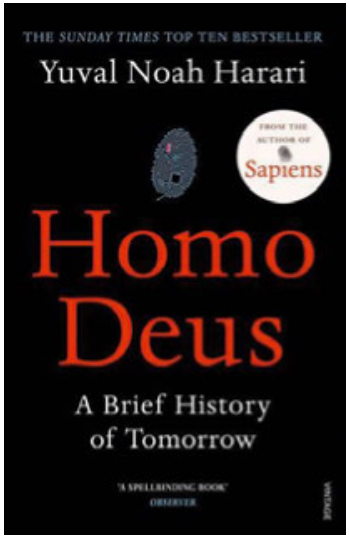

Yuval Noah Harari

Homo Deus

A Brief History of Tomorrow

London: Penguin Random House UK; 2017.

ISBN 978-1-78470-393-6

528 Seiten. $19.90 \mathrm{CHF}$.

Heute sind alle Organismen Algorithmen, und das Leben wird durch die Verarbeitung berechenbarer Datenprozesse definiert. Maschinenintelligenz hat sich vom menschlichen Bewusstsein abgekoppelt, und es ist nur eine Frage der Zeit, bis intelligente Algorithmen uns besser kennen als wir selbst. Yuval Noah Harari, der israelische Historiker, Bestsellerautor von Homo Sapiens, beendet mit diesen Prognosen sein zweites Sachbuch Homo Deus - eine kurze Geschichte von Morgen. Was aus den heutigen Bio- und Cyberwissenschaften werden könnte, beschreibt der Autor kenntnisreich und originell, mit Beispielen aus der Geschichte und Philosophie, verbunden durch verblüffend naheliegende Einsichten und originelle Hinweise aus zahlreichen weiteren Sachgebieten. Sein Erzählstil ist temporeich, witzig-ironisch, geradezu süffig unterhaltend und einprägsam, was we- sentlich die hohen Buchauflagen erklären dürfte. Gut Informierte haben vielleicht alles schon einmal in Fragmenten mitbekommen, andere erhalten ein Kompendium im Zeitraffer, das uns geradlinig von der Steinzeit zur künstlichen Intelligenz führt. Harari will ausdrücklich kein Prophet sein. Er schildert Möglichkeiten technischer Entwicklungen, die in Anfängen bereits zum Alltag gehören. Konzepte wie freier Wille und Individualität verlieren an Bedeutung, so der überwiegend pessimistische Grundton. Wenn einmal das Internet der Dinge vollständig realisiert sei, verlören die alten Illusionen von Autonomie ihre Bedeutung, der alte Mensch löst sich auf. Ein Vorreiter ist, wie häufig, die Medizin. Computerprogramme übernehmen die ärztliche Arbeit, präziser, schneller und weit umfassender, dank umfassendem Datamining, wie beispielsweise Watson, einer von IBM entwickelten Health-Plattform für ein digitales Gesundheitswesen, das alle Lebensbereiche umkrempeln wird. Dataisten, die Anhänger der neuen Religion, denken, wie die Kapitalisten vom freien Markt, dass eine unsichtbare Hand die Datenströme irgendwie richten wird. Am Ende überlassen wir das Denken den Maschinen, denn sie wissen es in jedem Fall besser. Dass eine säkulare Gesellschaft keine Chancen hat, den Kurs zu ändern, ergibt sich aus einer ärgerlichen Fehldefinition von $\mathrm{Hu}-$ manismus. Harari disqualifiziert diese Geistesrichtung kurzerhand als Religion oder Sekte. Ein Kernelement des liberalen Humanismus, die Willensfreiheit, wird, angeblich neurobiologisch widerlegt, wie ein altmodisches Relikt entsorgt. Ausser extremen religiösen und politischen Positionen bleibt keine ernsthafte Opposition mehr übrig. Eine gewagte Hypothese oder, besser noch, Geschichtsklitterung, die, der inszenierten Dramatik des Buches geschuldet, jedes alternative Denkmodell zum gegenwärtigen Trend ausschliesst.

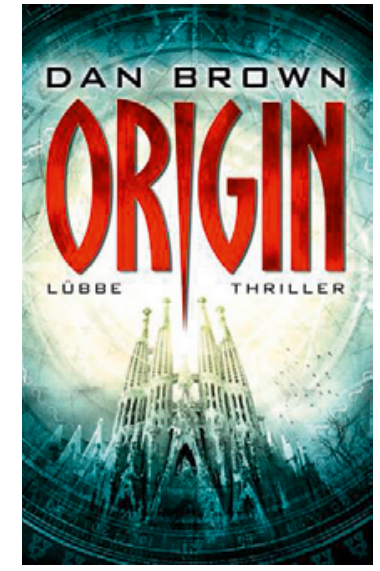

Dan Brown Origin

Köln: Bastei Lübbe; 2017. ISBN 978-0593078754 672 Seiten. 29.50 CHF.

Dan Brown, der Autor von The Da Vinci Code (Sakrileg), erzählt eine ähnliche Geschichte. Einen Thriller, in dem ein genialer Mathematiker den Übergang des Menschen zu einem Cyborg, einem Maschinenwesen, ankündet. Origin, sein neuster Bestseller, verbindet alle bekannten Ingredienzen. Finstere Kirchenmänner, Anhänger Francos, den Symbologen Robert Langdon und eine hübsche Kuratorin auf der Flucht, erbarmungslos gejagt von Bilbao bis Barcelona. Unterhaltender Kitsch auf hohem Niveau, die Botschaft ganz auf der Linie Hararis. Der Erste bietet eine informative Auseinandersetzung, der Zweite einen Reisser zum gleichen Thema. Beide Autoren kommentieren auf ihre Weise eine faszinierende und beängstigende Entwicklung, die rasend schnell und unkontrolliert, durch Finanzmacht und Militär getrieben, tiefgreifend unsere Welt verändert. 